\title{
Article
}

\section{Role of nursing associates in addressing the needs of people with dementia in hospital}

Smith, Michael and Gill, Tony

Available at http://clok.uclan.ac.uk/31614/

Smith, Michael ORCID: 0000-0003-2631-369X and Gill, Tony (2020) Role of nursing associates in addressing the needs of people with dementia in hospital. Nursing older people, 32 (1). ISSN 1472-0795

It is advisable to refer to the publisher's version if you intend to cite from the work. http://dx.doi.org/10.7748/nop.2020.e1231

For more information about UCLan's research in this area go to http://www.uclan.ac.uk/researchgroups/ and search for < name of research Group>.

For information about Research generally at UCLan please go to http://www.uclan.ac.uk/research/

All outputs in CLoK are protected by Intellectual Property Rights law, including Copyright law. Copyright, IPR and Moral Rights for the works on this site are retained by the individual authors and/or other copyright owners. Terms and conditions for use of this material are defined in the policies page.

\section{CLoK}

Central Lancashire online Knowledge www.clok.uclan.ac.uk

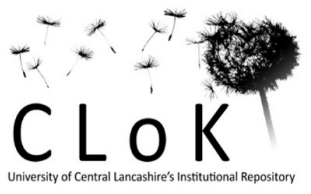




\title{
Role of nursing associates in addressing the needs of people with dementia in hospital
}

Michael Smith, Tony Gill

Citation

Smith M, Gill T (2019) Role of nursing associates in addressing the needs of people with dementia in hospital. Nursing Older People. doi: 10.7748/nop.2019.e1231

\section{Peer review}

This article has been subject to external double-blind peer review and has been checked for plagiarism using automated software

Correspondence

Msmith34@uclan.ac.uk

@MikeSmithUCLan

Conflict of interest

None declared

Accepted

30 September 2019

Online publication

$x x x$

\begin{abstract}
It is estimated that people with dementia make up around a quarter of all inpatients on acute hospital wards at any one time, although this is likely to be an underestimate. Healthcare assistants and other staff working in unregistered support roles often lack the training and skills, while nurses often lack the time, to provide optimal care for these patients. As a consequence, their needs are often unmet, their outcomes suboptimal compared with hospital inpatients who do not have dementia, and their quality of life reduced. The new nursing associates will have a hands-on role in patient care while their training equips them with the skills required to overcome communication barriers and identify patients' needs. This article explores the potential role of NAs in addressing the needs of people with dementia in hospital.
\end{abstract}

\section{Author details}

Michael Smith, lecturer in mental health nursing [correct? yes], School of Nursing, University of Central Lancashire, Preston, England; Dr Tony Gill, senior lecturer in mental health [correct? yes], School of Nursing, University of Central Lancashire, Preston, England.

\section{Keywords}


career pathways, communication, dementia, neurology, nurse-patient relations, nursing associates, nursing care, pain, patients, patient behaviour, patient outcomes, quality of life, support staff

Two of the main barriers preventing nursing staff from delivering effective person-centred care to hospitalised people living with dementia are a lack of skills or knowledge and a lack of time. The two staff groups who traditionally provide routine nursing interventions to hospital inpatients - many of whom will have dementia - are healthcare assistants (HCAs) and nurses. (The term HCA is used here as encompassing all nursing support roles that are not registered with the Nursing and Midwifery Council (NMC).) Both HCAs and nurses face barriers in providing effective support to people with dementia in hospital, albeit for different reasons: the former often lack the necessary skills, while the latter often lack the necessary time. This leads to care being delivered on a 'crisis intervention' model, with negative consequences for all involved. Nursing associates (NAs) may be able to bridge the gap, as they will be present on wards and equipped with the necessary skills to communicate effectively with patients with dementia, assess their needs and respond to them. This article discusses fundamental aspects of the care of people with dementia in the general hospital setting and explores the role NAs could play in identifying and addressing the needs of this patient population.

\section{Dementia care in acute hospitals}

People with dementia are substantial users of acute hospital care. It has been estimated that $25 \%$ of hospital beds in England are occupied by people with dementia at any one time, but informal reports suggest that this is an underestimate, with some hospitals stating that $40-50 \%$ of their patients have dementia (Boaden, 2016). The primary cause of admission to hospital is rarely dementia, but often an injury or condition such as hip fracture, urinary tract infection, chest infection or stroke (Boaden, 2016).

Tropea et al (2017) have identified that general hospitals do not always provide best-practice dementia care and that hospital staff encounter many barriers in caring for people with dementia, including the environment, staffing, workload, time, knowledge and skills. People with dementia admitted to hospital are known to have suboptimal outcomes compared with hospitalised patients who do not have dementia. They stay in hospital for longer, are more likely to be readmitted, and are more likely to die (Care Quality Commission 2013). The longer people with dementia stay in hospital, the worse their dementia symptoms and their physical health, and hospital admission often leads to discharge to residential care, rather than home (Boaden, 2016). Box 1 details some of the findings of the Care Quality Commission on dementia care in hospital.

\section{Box 1. Care Quality Commission findings on dementia care in hospital}

In a review of data from Hospital Episode Statistics from July 2011 to June 2012 regarding NHS acute trusts in England, the Care Quality Commission found that:

» In $29 \%$ of all hospital admissions of people with dementia, the person's dementia was not recorded during their most recent hospital admission despite it having been recorded in the past

» In $96 \%$ of trusts, people with dementia stayed in hospital significantly longer than those without dementia when admitted in an emergency

» in $76 \%$ of trusts, people with dementia stayed significantly longer than those without dementia when admitted for an elective procedure or treatment

》 In $70 \%$ of trusts, people with dementia were readmitted significantly more than people without dementia

» In $85 \%$ of trusts, people with dementia were significantly more likely to die in hospital than people without dementia

(Source: Care Quality Commission 2013)

The Prime Minister's Challenge on Dementia 2020 (Department of Health and Social Care 2015) highlighted the need to improve the assessment and care of people with dementia in hospitals, reduce the inappropriate prescribing of antipsychotic medication, and avoid inappropriate emergency admissions. Its implementation plan (DH 2016) called, among many other measures, for the creation of 'dementia-friendly' hospitals. The 2018 review of the implementation plan (DH, 2019) reported that work towards that commitment was generally on track, but that people with dementia in hospital were still experiencing care that 'fell short of the 2020 ambitions'. Two examples of areas where care was still suboptimal were meeting patients' nutritional needs and assessing patients for delirium (DH 2019). More is needed to ensure that the principles of dementia-friendly hospitals are embedded in practice and not seen as a tickbox exercise. 


\section{Lack of skills and lack of time}

One of the five principles of optimal dementia care in general hospitals proposed by Thompson and Heath (2012) under the acronym SPACE (see Box 2), is 'staff who are skilled and have time to care'. However, Thompson and Heath (2012) and Tropea et al (2017) have determined that two of the main barriers to hospital staff delivering effective care to people with dementia are a lack of skills or knowledge and a lack of time.

\section{Box 2. SPACE: five principles of optimal dementia care in general hospitals}

》Staff who are skilled and have time to care

》Partnership working with carers

》Assessment and early identification

»Care that is individualised

》 Environments that are dementia friendly

(Source: Thompson and Heath 2012)

On hospital wards, HCAs spend more time than nurses interacting with patients, but they often lack the skills to fully support those with dementia. Conversely, nurses have the required skills to communicate effectively with people with dementia, but often lack the time. Lack of skills and lack of time can lead to patients' needs not being identified, which in turn can lead to them being (wrongly) labelled as presenting 'challenging behaviour' (more appropriately termed 'reactive behaviour') [addition OK? yes]. In some cases, this is managed with antipsychotics or antidepressants even before patients have been assessed to understand the reason for their behaviour, which contradicts the dementia quality standard issued by the National Institute for Health and Care Excellence (NICE) (2019) - see Box 3 [OK to add Box 3? yes].

\section{Box 3. Quality statement 6: managing distress}

Quality statement 6 of the dementia quality standard (QS184) issued by the National Institute for Health and Care Excellence is that 'people with dementia have a structured assessment before starting non-pharmacological or pharmacological treatment for distress'. The rationale behind that quality statement is that 'people with dementia can become distressed, which can lead to symptoms such as increased aggression, anxiety, apathy, agitation, depression, delusions, hallucinations and sleep disturbances. But these behaviours may have other causes, including pain, delirium or inappropriate care. Understanding the causes of these behaviours and addressing them before offering treatment can prevent things getting worse and prevent any harm. It can also avoid the use of unnecessary interventions, such as antipsychotic medication and antidepressants, which may not manage the symptoms effectively'.

(Source: National Institute for Health and Care Excellence 2019)

Watson and Carberry (2014) identified that people with dementia often present with subtle signs of deterioration that may go unrecognised by staff who lack the appropriate training and skills. This can lead to delays in assessments and interventions, which can, in turn, negatively affect people's health, well-being and quality of life. Among all clinical staff on hospital wards, HCAs likely spend the most time providing fundamental care interventions to patients, including those with dementia, but they are also the staff who receive the least training. As part of the care certificate (a set of introductory skills and standards for non-regulated healthcare staff), HCAs undertake dementia awareness training, which corresponds to the first tiers of the Dementia Training Standards Framework set out by Health Education England (2018). In comparison, nurses receive much more extensive and in-depth training. Nurse education puts an emphasis on effective communication and 'the ability to communicate and manage relationships with people of all ages with a range of mental, physical, cognitive and behavioural health challenges'; it also equips them with the skills to identify and react to signs of deterioration or distress (NMC 2018a). However, as reported in Fukuda et al (2015), nurses in acute hospitals lack time to communicate with people with dementia and their families.

\section{Bridging the gap}

On the one hand, nurses increasingly undertake specialist tasks, make advanced clinical decisions and manage teams, therefore often delegating clinical interventions to others. This shift in nurses' roles increasingly takes them away from the bedside and from patients. On the other hand, HCAs have few opportunities to develop their clinical skills and knowledge and few prospects of career 
progression. The Shape of Caring review (Willis 2015) recommended to explore the development of a defined care role 'that would act as a bridge between the unregulated care assistant workforce and the registered nursing workforce'. This led to the creation of the role of NA in England.

The NA training programme started in January 2017. It is a two-year foundation degree that includes 3,000 hours of work-based and academic learning, with a minimum of 675 hours in placements. It exposes NA trainees to multidisciplinary working across a range of health and social care settings, which is designed to give them the ability to work with people of all ages and in a variety of settings (Vanson and Bidey 2019). Two cohorts, each composed of 1,000 trainees, started training in January and April 2017 , at 11 and 24 pilot sites respectively (Vanson and Bidey 2019). In 2019, the first NAs joined the NMC register, which in March 2019 counted 489 of them (NMC 2019). By January 2019, the number of NA training sites had increased to 65 (Vanson and Bidey 2019). The number of NAs is expected to rise dramatically in the next few years.

Like nurses, NAs are registered with, and regulated by, the NMC. In its standards of proficiency for NAs, the NMC (2018b) stipulates that they are skilled and accountable health professionals who are responsible for their actions, provide person-centred, safe and compassionate nursing care, and use their knowledge and experience to make evidence-based decisions and solve problems. The NMC lists a wide range of clinical assessments and interventions that NAs will be able to carry out (NMC, 2018b), which will free nurses' time to undertake more specialist tasks. Box 4 lists some of the procedures that NAs will be able to undertake, highlighted here as examples of how NAs will be equipped to care for people with dementia. In their pester presentation-on-the experience of NA trainees, Wright et al (2018) identified that NAs were able to spend-more time with patients than-nurses and apply their knowledge and skills to provide patients with optimal hands-on care.

\section{Box 4. Some procedures nursing associates will be able to undertake}

At the point of registration, nursing associates will be able to safely demonstrate the following procedures:

» 'Recognise signs of mental and emotional distress including agitation, or vulnerability'

»'Observe and monitor comfort and pain levels and rest and sleep patterns'

» 'Take appropriate action to ensure privacy and dignity at all times'

" 'Identify the need for and provide appropriate assistance with washing, bathing, shaving and dressing'

" 'Assist with feeding and drinking and use appropriate feeding and drinking aids'

》 'Assist with toileting, maintaining dignity and privacy and use appropriate continence products'

» 'Use appropriate assessment tools to determine, manage and escalate the ongoing risk of falls'

》'Recognise and take immediate steps to respond appropriately to uncontrolled symptoms and signs of distress including pain, nausea, thirst, constipation, restlessness, agitation, anxiety and depression'

》' 'Administer medication via oral, topical and inhalation routes'

" 'Manage and monitor effectiveness of symptom relief medication'

(Source: Nursing and Midwifery Council 2018b. Please note that this is not an exhaustive list and the above procedures are highlighted here as examples only. The full list is available from Nursing and Midwifery Council 2018b)

\section{Role of NAs in hospital dementia care}

There are several areas in which NAs will be well placed to identify and address the needs of hospital inpatients with dementia, notably:

» Building therapeutic relationships.

》Working with families.

» Understanding patients' behaviours.

》 Alleviating pain.

» Avoiding unnecessary sedation.

\section{Building therapeutic relationships}

Building therapeutic relationships is an important aspect of patient care in general. It is particularly important when caring for people with dementia because, as explained by Kitwood (1997) in his seminal work, the well-being of people with dementia often depends on the care, comfort and positive interactions provided by others and any decrease in their well-being may manifest as reactive behaviours. Building a therapeutic relationship with a person who has dementia will require enhanced communication skills as well as time (Downs and Collins 2015). Their training equips NAs with knowledge and experience from a range of disciplines, which 
will enable them to overcome communication barriers and see the patient as a whole person. Their understanding of dementia will enable them to guide the team (which is part of their role as members of the multidisciplinary team) to deliver more effective personcentred care.

\section{Working with families}

The families of people with dementia are important partners in care provision (Mendes 2018), partly because, as their informal carers, they possess expert knowledge of the person and can therefore assist in interpreting their behaviour. However, as reported in Bronson and Toye (2015), families of hospitalised people with dementia often feel left out. The authors of this article have observed that, when families enquire about their relative's condition or care, HCAs often refer them to a nurse. NAs will have the knowledge and confidence to communicate directly with families, keep them informed of their relative's condition or care, and involve them in the development of care plans and hospital passports. 'Supporting carers' is part of the NICE dementia quality standard (2019); having formed closer links with informal carers, NAs will be able to recognise their needs, offer them advice and support, and refer them for assessment and additional support where needed.

\section{Understanding patients' behaviours}

One of the issues in caring for people with dementia in the acute hospital environment is how to manage reactive behaviour. Researching the management of behavioural and psychological symptoms of dementia in the acute general hospital, White et al (2017) studied a longitudinal cohort of 230 patients with dementia admitted to two acute NHS hospitals. They found that $75 \%$ of patients displayed 'behavioural symptoms', aggression and activity disturbance being the most common ones. According to Stokes (2017), such behaviours are widely understood to be expressions of unmet need. A patient with dementia may feel fatigue, hunger, thirst, discomfort, pain, confusion, anxiety or fear, but not have the means to communicate this other than through behaviours that are, more than anything else, symptoms of stress or distress. NAs, by virtue of their enhanced knowledge and skills and the relationships they will have established with patients and families, will be in an optimal position to understand patients' behaviours and address their needs.

\section{Alleviating pain}

Pain is often under-recognised and under-treated in people with dementia (Feast et al 2018), because many lack the means of conveying their pain verbally and because unregistered staff may not be trained to recognise non-verbal cues indicating the presence of pain. NAs will be able to recognise and interpret subtle signs that a patient is experiencing pain, such as guarding, becoming more withdrawn or becoming more agitated; to formally assess pain by conducting a structured observational pain assessment; and to alleviate pain by requesting review by a prescriber and/or administering prescribed analgesics.

\section{Avoiding unnecessary sedation}

Making sense of patients' behaviours, alleviating their pain and generally addressing their needs will assist NAs in avoiding the unnecessary use of sedative medicines, such as antipsychotics and benzodiazepines. Antipsychotics are known to be harmful to the overall health of people with dementia (Ralph and Espinet 2019), increase their risk of stroke and be linked with a reduced life expectancy (Banerjee 2009). In older people with dementia- [is this correct, or should it be 'In older people', as in the title of Kim's article?], benzodiazepines are associated with increased risks of respiratory depression and falls (Kim 2015). Such adverse effects may further compromise people's health, affect their well-being, reduce their quality of life, and potentially result in death [could you please indicate a reference citation for this?] (Palmaro et al, 2015).

To manage agitation, aggression, distress and psychosis in people with dementia, NICE (2018) recommends exploring possible reasons for these symptoms and addressing clinical or environmental causes (such as pain, delirium or inappropriate care) before starting any treatment, whether non-pharmacological or pharmacological. Antipsychotics should only be used if people with dementia are at risk of harming themselves or others or if they experience agitation, hallucinations or delusions that are causing them severe distress. To reduce distress, agitation and aggression, NICE recommends offering psychosocial and environmental interventions, and personalised activities that promote engagement, pleasure and interest (NICE 2018). Livingstone et al (2014) found that engagement in pleasant activities, music therapy and positive interactions with carers were efficacious non-pharmacological interventions for agitation in dementia. 


\section{Conclusion}

While NAs will not be the panacea for all the challenges of caring for people with dementia in general hospitals, they will be well placed to address the needs of this patient population, using their enhanced skills and knowledge to provide optimal hands-on care. The authors of this article have heard anecdotal reports of how individual NAs were improving dementia care in general hospitals in Lancashire (but work needs to be done to capture this more formally). As this new profession establishes itself, it will be interesting to see how it contributes to the provision of care for people with dementia in hospital - an area that will warrant research.

\section{References}

Banerjee S (2009) The Use of Antipsychotic Medication for People with Dementia: Time for Action. DH. www.jcpmh.info/wp-content/uploads/time-for-action.pdf (Last accessed: 18 October 2019.)

Boaden A (2016) Fix Dementia Care: Hospitals. Alzheimer's Society, London. www.alzheimers.org.uk/sites/defaultffiles/migrate/downloads/fix dementia care hospitals.pdf (Last accessed: 4 November 2019.)

Bronson M, Toye C (2015) Providing information for family carers of hospital patients experiencing dementia. Dementia. 14, 2, 267-272. doi: $10.1177 / 1471301214560240$

Care Quality Commission (2013) Care Update, Issue 2. Care Quality Commission, London. www.cqc.org.uk/publications/major-report/care-update-issue-2 (Last accessed: 4 November 2019.)

Department of Health and Social Care (2015) Prime Minister's Challenge on Dementia 2020. www.gov.uk/government/publications/prime-ministers-challenge-ondementia-2020 (Last accessed: 18 October 2019.)

Department of Health and Social Care (2016) Prime Minister's Challenge on Dementia 2020. Implementation Plan. www.gov.uk/government/uploads/system/uploads/attachment_data/file/507981/PM_Dementia-main_acc.pdf (Last accessed: 21 October 2019.)

Department of Health and Social Care (2019) Dementia 2020 Challenge: 2018 Review Phase 1.

https://assets.publishing.service.gov.uk/government/uploads/system/uploads/attachment_data/file/780777/dementia-2020-challenge-2018-review.pdf (Last accessed: 4 November 2019.)

Downs M, Collins L (2015) Person-centred communication in dementia care. Nursing Standard. 30, 11, 37-41. doi: 10.7748/ns.30.11.37.s45.

Feast AR, White N, Lord K et al (2018) Pain and delirium in people with dementia in the acute general hospital setting. Age and Ageing. 47, 6, 841-846. doi: 10.1093/ageing/afy112.

Fukuda R, Shimizu Y, Seto N (2015) Issues experienced while administering care to patients with dementia in acute care hospitals: a study based on focus group interviews. International Journal of Qualitative Studies on Health and Well-Being. 10, 25828. doi: 10.3402/qhw.v10.25828.

Health Education England (2018) Dementia Training Standards Framework. www.hee.nhs.uk/our-work/dementia-awareness/core-skills (Last accessed: 18 October 2019.)

Palmaro, A., Dupouy, J., \& Lapeyre-Mestre, M. (2015). Benzodiazepines and risk of death: Results from two large cohort studies in France and UK. European Neuropsychopharmacology, 25(10), 1566-1577. Doi: 10.1016/j.euroneuro.2015.07.006

Kim AP (2015) Continued use of benzodiazepines in older adults. Hospital Pharmacy. 50, 7, 557-558. doi: 10.1310/hpj5007-557.

Kitwood TM (1997) Dementia Reconsidered: The Person Comes First. McGraw-Hill, New York NY.

Livingston G, Kelly L, Lewis-Holmes E et al (2014) Non-pharmacological interventions for agitation in dementia: systematic review of randomised controlled trials. British Journal of Psychiatry. 205, 6, 436-442. doi: 10.1192/bjp.bp.113.141119.

Mendes A (2018) Supporting the family and relationships of a person with dementia in hospital. British Journal of Nursing. 27, 6, 340. doi: 10.12968/bjon.2018.27.6.340.

National Institute for Health and Care Excellence (2018) Dementia: Assessment, Management and Support for People Living with Dementia and their Carers. www.nice.org.uk/guidance/ng97 (Last accessed: 5 November 2019.)

National Institute for Health and Care Excellence (2019) Dementia. Quality standard [QS184]. www.nice.org.uk/guidance/QS184 (Last accessed: 4 November 2019.)

Nursing and Midwifery Council (2018a) Standards of Proficiency for Registered Nurses. www.nmc.org.uk/globalassets/sitedocuments/education-standards/future-nurseproficiencies.pdf (Last accessed: 4 November 2019.)

Nursing and Midwifery Council (2018b) Standards of Proficiency for Nursing Associates. www.nmc.org.uk/globalassets/sitedocuments/education-standards/nursingassociates-proficiency-standards.pdf (Last accessed: 18 October 2019.) 
Nursing and Midwifery Council (2019) The NMC Register: 31 March 2019. www.nmc.org.uk/globalassets/sitedocuments/other-publications/nmc-register-data-march19.pdf (Last accessed: 4 November 2019.)

Ralph SJ, Espinet AJ (2019) Use of antipsychotics and benzodiazepines for dementia: time for action? What will be required before global de-prescribing? Dementia 18, 6, 2322-2339. doi: 10.1177/1471301217746769.

Stokes G (2017) Challenging Behaviours in Dementia: A Person Centred Approach. Routledge, London.

Thompson R, Heath H (2012) Dementia - Commitment to the Care of People with Dementia in Hospital Settings. Royal College of Nursing, London. https://dementiapartnerships.com/wp-content/uploads/sites/2/rcnhospitalcare.pdf (Last accessed: 18 October 2019.)

Tropea J, LoGiudice D, Liew D et al (2017) Caring for people with dementia in hospital: findings from a survey to identify barriers and facilitators to implementing best practice dementia care. International Psychogeriatrics. 29, 3, 467-474. doi: 10.1017/S104161021600185X.

Vanson T, Bidey T (2019) Introduction of Nursing Associates: Year 2 Evaluation Report. www.hee.nhs.uk/sites/default/files/documents/15.1\%20\%20Trainee\%20Nursing\%20Associate\%20Year\%202\%20Evaluation\%20Report_1.pdf (Last accessed: 4 November 2019.)

Watson D, Carberry M (2014) Training HCAs to recognise patient deterioration. Nursing Times. 110: online issue.

White N, Leurent B, Lord K et al (2017) The management of behavioural and psychological symptoms of dementia in the acute general medical hospital: a longitudinal cohort study. International Journal of Geriatric Psychiatry. 32, 3, 297-305. doi: 10.1002/gps.4463.

Willis P (2015) Raising the Bar: Shape of Caring - A Review of the Future Education and Training of Registered Nurses and Care Assistants www.hee.nhs.uk/sites/default/files/documents/2348-Shape-of-caring-review-FINAL.pdf (Last accessed: 18 October 2019.)

Wright K, Fielding S, Lord L et al (2018) Having the Time to Care! Nursing Associates: the Future. Poster presented at 7 th European Conference on Mental Health, 19-21 September 2018, University of Central Lancashire, Preston [I cannot find this conference listed anywhere; could you please check that all the details are correct and amend them if/where needed?]. 